\title{
Facilitation of attitude formation through communication: how perceived source expertise enhances the ability to achieve cognitive closure about complex environmental topics
}

\author{
Charlotte Koot, Emma ter Mors, Naomi Ellemers, Dancker D. L. Daamen \\ Department of Social and Organizational Psychology, Leiden University
}

\author{
Correspondence concerning this article should \\ be addressed to Emma ter Mors, Department \\ of Social and Organizational Psychology, \\ Leiden University, Wassenaarseweg 52, 2300 \\ RB Leiden, The Netherlands. \\ E-mail: emors@fsw.leidenuniv.nl \\ Current address: Naomi Ellemers, Faculty of \\ Social Sciences, Utrecht University, \\ Heidelberglaan 1, 3508, TC, The Netherlands \\ Dancker Daamen passed away in September \\ 2012.
}

doi: 10.1111/jasp.12391

\begin{abstract}
Attitudes on which people have achieved cognitive closure are better predictors of future attitudes and behavior than open attitudes. In two experiments, we found that factors in communication (source identity, source consensus) can enhance people's ability to achieve cognitive closure on complex environmental topics through an increase in perceived source expertise. Results showed that participants perceived higher levels of source expertise and felt better able to achieve cognitive closure on the environmental technology of carbon dioxide capture and storage (CCS) when the information source had an expert identity compared to a non-expert identity. The communication of consensus by the information source increased the level of expertise ascribed to the non-expert source, resulting in an enhanced ability to achieve closure.
\end{abstract}

\section{Introduction}

The public discourse in today's society is increasingly characterized by highly complex issues, such as the threat of climate change. Due to the multifaceted nature of such topics, people do not always feel capable of forming a definite or "closed" attitude. Yet, closed attitudes-attitudes about which people have achieved a state of cognitive closure-are known to be more stable and predictive of actual behavior than "unfinished" or open attitudes (cf. Bassili, 1996; Fazio \& Zanna, 1978; Krosnick \& Petty, 1995; Petty \& Cacioppo, 1986). To better explain or predict actual behavior, it is therefore important to understand the factors that lead people to achieve a state of cognitive closure. The present research investigates how one such precursor of cognitive closure-the ability to achieve closure-can be influenced in the context of information provision about a complex environmental topic. We examine whether and how the identity of an information source and the communication of consensus influence people's perceptions of source expertise, and in this way impact on their ability to achieve closure.

\section{The ability to achieve cognitive closure}

Research on precursors of cognitive closure has so far primarily focused on people's need for closure. People tend to differ from each other in the extent to which they feel compelled to reach and maintain a state of closure in their attitudes (e.g., Kruglanski, Dechesne, Orehek, \& Pierro, 2009; Kruglanski \& Webster, 1996; Webster \& Kruglanski, 1994, 1997). More recent work has also started paying attention to the idea that people differ in their ability to achieve cognitive closure, i.e., whether they manage to make up their mind and decide what they think about specific topics, or feel unable to do so (e.g., Kossowska \& Bar-Tal, 2013; Roets \& Soetens, 2010; Roets \& Van Hiel, 2007).

Recent research has demonstrated that the extent to which people feel able to achieve closure is an important determinant of the actual achievement of cognitive closure (Koot, Ter Mors, Ellemers, \& Daamen, 2014). In this work, the ability to achieve closure is defined as the perceived ability to make judgments and decisions confidently and with certainty (cf. Roets \& Van Hiel, 2007). This research revealed that people's perceived ability to achieve closure positively influences the level of cognitive closure that they achieve. Furthermore, it demonstrated that the extent to which people feel able to achieve closure can also be influenced by (experimentally manipulated) external factors, instead of solely representing a stable individual difference factor (see also Kossowska, Dragon, \& Bukowski, 2015). Only a few studies so far have 
manipulated the ability to achieve closure, and have done so by employing relatively artificial experimental procedures. The next question thus is which factors tend to have such effects in daily life. We complement prior work that has revealed the importance of source characteristics in judging the value of opinion-relevant information (e.g., Bohner \& Dickel, 2011; Ter Mors, Weenig, Ellemers, \& Daamen, 2010). In the present research, we examine two factors in communication-source identity and consensus-that may influence the perceived expertise of an information source, and hence predict people's ability to form a closed attitude on a complex environmental topic.

\section{Perceived source expertise and the ability to achieve closure}

Given the extensive information from many different sources that is available (e.g., through online communication), not all information will be equally helpful for the formation of a closed attitude. We propose that people feel particularly strengthened in their ability to make up their mind about complex environmental issues when they are consulting or receiving information from a source that they consider to be knowledgeable. The formation of closed vs. open attitudesand people's willingness to take a stance-has so far not been systematically examined in relation to their ability to achieve closure. This is why we derive predictions from available knowledge in the literature, even is this concerns other aspects of attitude formation, namely people's willingness to change their attitudes once they are formed. Prior research on attitude change suggests that source expertise is likely to be relevant. That is, identical information often seems more convincing and has a greater impact on the content of people's attitude when originating from a source that is regarded as having high expertise, compared to low expertise (e.g., Briñol \& Petty, 2009; Cialdini \& Goldstein, 2004; Pornpitakpan, 2004). The relevance of source expertise is also acknowledged in contemporary theories of persuasion such as the Elaboration Likelihood Model (ELM: Petty \& Cacioppo, 1986) and the Unimodel (Kruglanski \& Thompson, 1999). Specifically, Briñol and Petty (2009) have argued that-under highelaboration conditions-source factors can elicit metacognitive processes (i.e., thoughts about our own thoughts or thought processes). They also review empirical evidence suggesting that source credibility can increase the level of confidence that people have in their own issue-related thoughts when developing their attitudes. Furthermore, it has been shown that people are more certain of their attitudes when these are based on information that stems from a credible source than from a low-credible source (Clarkson, Tormala, \& Rucker, 2008). Based on this prior work on metacognitive processes in persuasion, we argue that source expertise might also impact the confidence that people have in their ability to achieve closure. We propose that people feel better able to achieve cognitive closure on the basis of information provided when they perceive the source of this information to have high, rather than low, relevant expertise.

\section{Identity and consensus as indicators of source expertise}

If perceived source expertise is indeed important for people's ability to achieve closure, this raises the question of what determines people's impressions of source expertise. In the present research, we propose two determinants of perceptions of source expertise, namely who is providing the information (source identity) and what message is being communicated (consensus vs. non-consensus).

First, we argue that people may consider the identity of an information source to gain a sense of its expertise. That is, when different individuals or stakeholders provide information, merely knowing who they are or which body they represent can indicate the source's knowledgeability (e.g., Reimer, Mata, \& Stoecklin, 2004). For instance, knowing whether a statement is made by a random person in the street, a relevant professional, or a journalist already influences the perceived likelihood that this source has relevant expertise about the topic in question. Which of these parties is most likely to offer expert information further depends on the issue under consideration. When receiving information on the energy efficiency of biofuels, for instance, knowing that this information was provided by a professor of sustainability will lead people to infer high source expertise, because an academic title in a relevant field suggests that years of high-level education, training, and professional experience are contained in the information provided. This is less likely to be the case, however, when a neighbor proclaims his or her beliefs about a potential side effect of biodiesel compared to that of regular diesel, as this most probably reflects individual views, very limited case observations, or unwarranted hearsay. We therefore predict that relevant features indicating the identity of an information source determine people's perceptions of the source's expertise. Furthermore, we predict that when people attribute high expertise to a source on the basis of its identity, this should lead them to feel better able to achieve cognitive closure compared to when they believe the source to have little relevant expertise.

Second, we argue that for perceptions of source expertise it may not only matter who provides the information, but that it is also important what message the information source communicates. Prior research has tended to consider sources of information either as being a particular individual, or as a unified entity, representing a single particular stance or opinion. In real life, however, a source of information is also likely to constitute of a collection of individuals. Think, for example, of branch organizations that represent professionals or of 
citizens' associations that represent members of the general public. Particularly in the case of complex and multi-faceted topics, it is not self-evident that all individuals represented by the organization are in full agreement with each other, or focus on the same information aspects, even if they are experts. For example, an organization that represents climate change scientists can provide information about different technologies that have been developed to reduce greenhouse gas emissions, while explaining that there are conflicting views among the scientists concerning which of these technologies can be best employed. In view of our current research interest, the question is how the communication of such (lack of) consensus affects the perceived expertise of the source of information in question among message recipients, and what the consequences are for message recipients' perceived ability to achieve closure on the topic. We anticipate that agreement about relevant concerns or conclusions will generally be seen as contributing to the perceived expertise of the source, as it evokes the impression that its members draw on a common and objective knowledge base and that they "know what they are talking about." This resonates with prior work on persuasion, suggesting that "consensus may imply correctness" (e.g., Darke et al., 1998; Eagly \& Chaiken, 1993; Prislin, Shaffer, \& Crowder, 2012; Ziegler, Diehl, Zigon, \& Fett, 2004). In this prior work, the degree of consensus tends to be operationalized as the extent to which a specific position is supported (e.g., by a numeric majority or minority). This work revealed that people are more inclined to change their attitudes in line with majority-rather than minority-views (for overviews, see Crano \& Seyranaion, 2007; Wood, Lundgren, Quelette, Busceme, \& Blackstone, 1994). Our approach differs, however, as non-consensus in the present study is operationalized by explicitly stating that the information source (e.g., a branch organization or citizens' association) expresses internal disagreement about the appropriate stance regarding the target topic ("some of us think a, others think b”).

We extend prior work suggesting that source consensus may influence attitude change and formation through metacognitive processes under high elaboration conditions (e.g., Briñol \& Petty, 2009; Horcajo, Petty, \& Briñol, 2010; Tormala \& DeSensi, 2009). Prior work has shown that sources representing a numerical majority (vs. minority) can increase the level of confidence in the thoughts people have about a message, and this impacts their attitudes (e.g., Horcajo et al., 2010). Based on these findings elucidating the relevance of majority agreement for persuasion, we argue that source consensus is likely to enhance people's perceived ability to achieve closure. Specifically, we predict that people perceive more source expertise when an information source communicates consensus rather than non-consensus. Furthermore, we predict that when people attribute high expertise to a source that communicates consensus, this should lead them to feel better able to achieve closure compared to when an information source communicates disagreement-as this does not contribute to perceived expertise. Thus, we argue that perceptions of source expertise do not only depend on the identity of the source or its objective level of expertise, but likely also depend on the degree of consensus expressed by the source.

Lastly, in the present research we explore the possibility that the impact of communicating (non-)consensus on perceived expertise depends on the identity of the source. In this way, we also extend existing knowledge on potential interaction effects of source factors in attitude change and formation (cf. Ziegler et al., 2004). We anticipate that the communication of consensus might particularly increase the perceived expertise of a source (hence increasing people's ability to achieve closure) whose expertise seems to be low on the basis of its identity. For instance, when citizens who have no particular knowledgeability on climate change all agree (consensus) that their garden plants coming into bloom earlier every year is a sign of global warming and communicate this, this may suggest some shared expertise based on lay observations, even if their observations are inaccurate or remain unverified. It is less evident whether there is added value in communicating consensus when high expertise is already clearly implied in the identity of the source. Hence we anticipate that the impact of source consensus on perceived expertise may depend on the identity of the source.

\section{Overview of the present research}

We examine the importance of perceptions of source expertise for people's ability to achieve cognitive closure about complex environmental topics in two experimental studies. Specifically, we assess whether and how the identity of an information source and the communication of (non-)consensus affect perceived source expertise. Moreover, we investigate how these effects on perceptions of source expertise in turn influence people's ability to achieve closure. The experiments will be conducted in the context of the complex environmental topic of carbon dioxide capture and storage technology (CCS); a potential climate change mitigation technology that is considered important for stabilizing greenhouse gas concentrations in the atmosphere (IPCC, 2007). ${ }^{1}$ Because past research suggests that metacognitive processes occur under high elaboration conditions (e.g., Briñol \& Petty, 2009; Horcajo et al., 2010; Tormala \& DeSensi, 2009), in both experiments the topic of CCS is presented as a topic of

${ }^{1} \mathrm{CCS}$ involves the capture of $\mathrm{CO}_{2}$ produced in power plants or other industrial sources, transportation of the $\mathrm{CO}_{2}$ to underground storage sites (e.g., depleted oil and gas fields), and long-term storage in these sites. As with other complex technologies, public acceptance is a critical factor in the successful implementation of CCS (e.g., Markusson, Ishii, \& Stephens, 2011; Terwel et al., 2012). 
personal relevance to participants. In both experiments, the identity of the information source is manipulated by explaining to participants that they are to receive information on CCS from either the "Association of Citizens and Sustainability" or the "Association of Dutch Geophysicists and Sustainability." In Experiment 2, we additionally manipulate source consensus by explaining that the members of the information source either agree or disagree among themselves regarding the consequences of CCS for the environment. The level of source expertise that participants perceive and the extent to which they feel able to achieve closure are measured in both experiments as central outcome variables. Additionally, in Experiment 2, participants are actually provided with information on CCS that ostensibly originates from the information source and in which consensus or non-consensus is communicated. In this study, we then also measure the extent to which participants achieve cognitive closure in their attitude formation towards the implementation of CCS with both a self-report and a behavioral measure. We test the following hypotheses:

Hypothesis 1. We argue that people will perceive an association of relevant professionals to have higher expertise on CCS than an association of citizens, and that this higher level of perceived expertise in turn increases people's ability to achieve closure on the complex topic of CCS. As a result, we predict that source identity will indirectly influence ability to achieve closure through perceived source expertise.

Hypothesis 2. We argue that people will perceive an information source that communicates consensus to have higher expertise than a source that communicates non-consensus, and that this higher level of perceived expertise in turn increases people's ability to achieve closure on the complex topic of CCS. We thus predict that source consensus will indirectly influence ability to achieve closure through perceived source expertise.

Additionally, we will explore whether or not the indirect effect of consensus on ability to achieve closure, as predicted in Hypothesis 2, applies equally to both types of sources examined (an association of professionals vs. an association of citizens). We anticipate that the added value of consensus as an indicator of expertise may be particularly evident in the case of a lay source (an association of citizens).

\section{Experiment 1}

The aim of Experiment 1 was to test our prediction that the identity of an information source affects perceptions of source expertise, and in this way indirectly influences people's ability to achieve closure on a complex environmental topic (Hypothesis 1). Initial support for this hypothesis was found in a preliminary study that was set up, among other things, to explore the effects of source identity on perceived source expertise and ability to achieve closure. In this preliminary study, we used a similar setup and an identical source identity manipulation as in Experiment 1, but were unable to achieve random allocation to conditions because data for the two source identity conditions were collected separately and several months apart from each other. Nevertheless, data from this preliminary study revealed that university students $(N=89)$ perceived higher levels of source expertise ( $\alpha=.92$, $\left.F[1,87]=23.31, p<.001, \eta_{\mathrm{p}}{ }^{2}=.21\right)$ and perceived themselves to be better able to achieve closure on CCS ( $\alpha=.68$, $\left.F[1,87]=7.53, p=.007, \eta_{\mathrm{p}}{ }^{2}=.08\right)$ when anticipating to receive information from Geophysicists than from the Citizens Association. Further, perceived source expertise was found to mediate the effect of source identity on ability to achieve closure in this sample (indirect effect $B=0.23,95 \%$ CI $[0.06,0.49]$; c' path $B=0.28, p=.175)$. These data provide initial support for Hypothesis 1 and for the effectiveness of the source identity manipulation and experimental procedure we developed to examine this. In Experiment 1, we sought to test the robustness of these findings under more controlled circumstances.

\section{Method}

\section{Participants and design}

Seventy social science and humanities undergraduate students ( 19 men and 51 women, $M_{\text {age }}=20.90, S D=3.58$ ) from Leiden University participated in this experimental study and were randomly assigned to either one of the source identity conditions (the Citizens Association condition or the Geophysicists condition). Participants received a monetary reward or course credit in return for their participation.

\section{Procedure}

The experiment was the first in a series of unrelated studies. Upon arrival at the laboratory, participants were led to individual cubicles, each containing a PC on which the study would be conducted. Participants first read an introductory text on climate change and carbon dioxide capture and storage technology (CCS). They then learned that CCS would possibly be implemented in the west of the Netherlands, which is the region where the participants lived or to which they were tied in other ways, and where Leiden University is located. The study was introduced as a study on the attitudes of inhabitants of the west of the Netherlands towards the potential implementation of CCS in this region. Next, participants were told that before they were to report their attitudes on the implementation of CCS, they would receive more information on the topic. Participants learned that there are various bodies and organizations that provide 
information on CCS and that they would receive information from one of these sources. They also learned that not every participant would receive information from the same source, and that some information sources might appeal more than others. As a manipulation of source identity, participants were either told that they would receive information from "the Association of Citizens and Sustainability" or that they would receive information from "the Association of Dutch Geophysicists and Sustainability." Both these information sources were fictitious.

Participants in the Citizens Association condition read:

In your case the information about carbon dioxide capture and storage technology and its implementation in the west of the Netherlands is coming from the Association of Citizens and Sustainability. This association is concerned with developments regarding sustainability and consists of Dutch citizens: These are people with diverse backgrounds who are interested in the topic. The Association of Citizens and Sustainability has listed information about aspects and characteristics of carbon dioxide capture and storage technology in the west of the Netherlands that in their view are the most important.

Participants in the Geophysicists condition, on the other hand, read:

In your case the information about carbon dioxide capture and storage technology and its implementation in the west of the Netherlands is coming from the Association of Dutch Geophysicists and Sustainability. This association is concerned with developments regarding sustainability and consists of geophysicists: These are experts who are specialized in the topic. The Association of Dutch Geophysicists and Sustainability has listed information about aspects and characteristics of carbon dioxide capture and storage technology in the west of the Netherlands that in their view are the most important.

Participants then completed the manipulation check of the source identity manipulation and completed measures of perceived source expertise and ability to achieve closure. At the end of the series of studies in which the participants took part, participants were thanked and debriefed. They also learned that they would not receive additional information on CCS.

\section{Measures}

Depending on experimental condition, participants either answered questions relating to (information from) the Association of Citizens and Sustainability or relating to (information from) the Association of Dutch Geophysicists and
Sustainability. For reasons of legibility, we refer to both associations using the term "the information source" in our presentation of the dependent variables below.

Manipulation check. To check whether participants had correctly understood the identity of the information source, they were asked the following question: "Is the information that you are about to read about carbon dioxide capture and storage technology provided by the information source?" $(1=$ yes; $2=$ no $)$.

Perceived source expertise. The level of expertise that the participants ascribed to the information source was measured using a 4-item questionnaire. Participants were asked to indicate their agreement with the following statements: "I think that the members of the information source know a lot about carbon dioxide capture and storage technology," "I think that the members of the information source are knowledgeable about carbon dioxide capture and storage technology," "I think that the information source is a specialist in the area of carbon dioxide capture and storage technology," and "I think that the information source has expertise in the area of carbon dioxide capture and storage technology" ( 1 = completely disagree, $7=$ completely agree $)$. A perceived source expertise scale was calculated by averaging participants' responses to the items $(\alpha=.93)$.

Ability to achieve closure. Participants' perception regarding their ability to achieve closure on CCS was measured by means of a 4-item questionnaire. Participants were asked to indicate their agreement with the following statements: "I think that I can form a clear opinion on the implementation of carbon dioxide capture and storage technology in the west of the Netherlands on the basis of the information of the information source," "I expect that after reading the information of the information source I will be certain of my opinion on the implementation of carbon dioxide capture and storage technology in the west of the Netherlands," "I expect that after reading the information of the information source my opinion on the implementation of carbon dioxide capture and storage technology in the west of the Netherlands will be fixed," and "I think that after reading the information of the information source I will still have a need for extra information about carbon dioxide capture and storage technology" (reverse-coded) $\quad(1=$ completely disagree, $7=$ completely agree). An ability to achieve closure score was calculated by averaging participants' responses to the items $(\alpha=.66)$.

\section{Results}

Manipulation check. We screened the data for incorrect answers to the manipulation check. Two of the 70 
participants had incorrectly understood the identity of the information source. We excluded these cases from the analyses reported below; accordingly, the analyses reported below were performed on the data of 68 participants. Inclusion of all cases did not change the pattern of results.

Perceived source expertise. Analysis of variance (ANOVA) showed a significant effect of source identity on perceived source expertise, $F(1,66)=57.75, \quad p<.001$, $\eta_{\mathrm{p}}{ }^{2}=.47$. As predicted, and consistent with the results of the preliminary study, participants in the Geophysicists condition ascribed higher levels of expertise to the information source $(M=5.66, S D=0.62)$ compared to participants in the Citizens Association condition $(M=3.89, S D=1.21)$.

Ability to achieve closure. ANOVA revealed a marginally significant effect of source identity on ability to achieve closure in the predicted direction, $F(1,66)=3.07$, $p=.085, \eta_{\mathrm{p}}{ }^{2}=.04$. That is-replicating the results of our preliminary study-participants in the Geophysicists condition felt better able to achieve closure in their attitudes on CCS $(M=3.61, S D=0.92)$ compared to participants in the Citizens Association condition $(M=3.21, S D=0.95)$.

Mediation analysis. We followed a bootstrapping procedure (Preacher \& Hayes, 2008: 5000 resamples, bias corrected) to examine whether or not perceived source expertise mediated the effect of source identity on ability to achieve closure. The results indeed revealed a significant indirect effect of the source identity manipulation ( $0=$ Citizens Association, $1=$ Geophysicists) on ability to achieve closure through perceived source expertise $(B=0.65,95 \%$ CI $[0.31$, 1.11 ; c' path $B=-0.24, p=.411$ ), thereby providing additional support for Hypothesis 1.

\section{Discussion}

Results of Experiment 1 provide support for our argument that when people believe an information source to have high expertise, they consider themselves to be more capable of forming a closed attitude than when they perceive the source to have low expertise on the topic in question. Specifically, we found that level of expertise that participants ascribed to the information depended on the identity of the source, and that perceived expertise in turn affected people's ability to achieve closure. Providing support for Hypothesis 1, and consistent with the results of the preliminary study, participants perceived the Geophysicists to have higher relevant expertise than the Citizens Association, and as a consequence, participants felt better able to achieve closure on the complex environmental topic of carbon dioxide capture and storage technology (CCS) when anticipating information from the Geophysicists.

\section{Experiment 2}

The design of Experiment 2 was similar to that of Experiment 1 . As in the previous study, we varied the identity of the information source from which participants expected to receive information on carbon dioxide capture and storage technology (CCS), to obtain additional support for Hypothesis 1 . In the present study, we also varied the level of consensus in the source in a $2 \times 2$ design. That is, participants additionally learned that there was agreement or disagreement among members of the information source regarding the consequences of CCS for the environment, to examine support for Hypothesis 2. In this study-after completing the central outcome measures of perceived source expertise and ability to achieve closure-participants actually received information on CCS that ostensibly originated from the information source and in which consensus or nonconsensus was communicated. After participants had read this information, we measured the extent to which they actually achieved cognitive closure in their attitude towards the implementation of CCS (see also Koot et al., 2014). In extension of Experiment 1, we included additional measures in the present study to control for individual differences in general need to achieve closure (Webster \& Kruglanski, 1994) and overall self-efficacy (Bandura, 1977, 2006).

\section{Method}

\section{Participants and design}

Eighty-six social science and humanities undergraduate students (22 men and 64 women, $\left.M_{\text {age }}=20.76\right)$ from Leiden University participated in Experiment 2 and were randomly assigned to one of the conditions of the 2 (source identity: Citizens Association vs. Geophysicists) $\times 2$ (source consensus: consensus vs. non-consensus) between-participants factorial design. Participants received a monetary reward or course credit in return for their participation.

\section{Procedure}

Experiment 2 was the first study in a series of unrelated studies. The study followed the same procedure as Experiment 1 up to the point where the source identity manipulation was introduced. The source identity manipulation-Citizens Association vs. Geophysicists - was identical to the manipulation in Experiment 1. However, instead of the last sentence of the manipulation ("The information source has listed information about aspects and characteristics of carbon dioxide capture and storage technology in the west of the Netherlands that in their view are the most important."), the consensus manipulation was introduced. Depending on experimental condition, participants read (manipulated information in italics): 
The Association of Citizens and Sustainability/the Association of Dutch Geophysicists and Sustainability has listed what in their view are the most important consequences of carbon dioxide capture and storage technology for the environment. You are about to read this information. It is good to know that the members of the Association of Citizens and Sustainability/the Association of Dutch Geophysicists and Sustainability agree/disagree among themselves about the net effect of carbon dioxide capture and storage technology for the environment. In other words; the members all draw the same conclusion/do not all draw the same conclusion. This also appears from the information of the Association of Citizens and Sustainability/the Association of Dutch Geophysicists and Sustainability.

Participants then completed manipulation checks of source identity and consensus and they completed measures of the central outcome variables of perceived source expertise and ability to achieve closure. Next, participants read information on CCS that ostensibly originated from the announced source (Citizens Association or Geophysicists) and in which (non-) consensus was expressed. In all experimental conditions, the information from the source consisted of the same two arguments that were based on the CCS argument map by Van Egmond and Hekkert (2012); one argument reasoning why the effects of CCS for the environment would be positive and one argument reasoning why the effects would be negative. In the consensus condition, members of the source agreed on the net effect of CCS for the environment. The conclusion of the source on this topic was counterbalanced (i.e., an overall positive effect of CCS for the environment or an overall negative effect). Half of the participants in the consensus condition read (manipulated information in italics):

The members of the Association of Citizens and Sustainability/the Association of Dutch Geophysicists and Sustainability agree among themselves about the net effect of carbon dioxide capture and storage technology for the environment. This is what they have to say about it:

"The members of our association think that the effect of carbon dioxide capture and storage technology for the environment is positive, since the technology reduces $\mathrm{CO}_{2}$ emissions and thereby fights climate change. Indeed, large amounts of chemical waste are produced with the capture of $\mathrm{CO}_{2}$, but according to our members this does not outweigh the advantage of fighting climate change."

The other half of the participants in the consensus condition read (manipulated information in italics):

The members of the Association of Citizens and Sustainability/the Association of Dutch Geophysicists and
Sustainability agree among themselves about the net effect of carbon dioxide capture and storage technology for the environment. This is what they have to say about it:

"The members of our association think that the effect of carbon dioxide capture and storage technology for the environment is negative, since large amounts of chemical waste are produced with the capture of $\mathrm{CO}_{2}$. Indeed, carbon dioxide capture and storage technology reduces $\mathrm{CO}_{2}$ emissions and thereby fights climate change, but according to our members this does not outweigh the disadvantage of chemical waste."

In the non-consensus condition, on the other hand, members of the source disagreed on the net effect of CCS for the environment. The same two arguments as in the consensus condition were used, and the order in which they were presented was counterbalanced. Half of the participants in the non-consensus condition read (manipulated information in italics):

The members of the Association of Citizens and Sustainability/the Association of Dutch Geophysicists and Sustainability disagree among themselves about the net effect of carbon dioxide capture and storage technology for the environment. This is what they have to say about it:

"Some members of our association think that the effect of carbon dioxide capture and storage technology for the environment is positive, since the technology reduces $\mathrm{CO}_{2}$ emissions and thereby fights climate change. Others find that this advantage does not outweigh an important disadvantage-being that large amounts of chemical waste are produced with the capture of $\mathrm{CO}_{2}$. They think that the effect of carbon dioxide capture and storage technology for the environment is negative."

The other half of the participants in the non-consensus condition read (manipulated information in italics):

The members of the Association of Citizens and Sustainability/the Association of Dutch Geophysicists and Sustainability disagree among themselves about the net effect of carbon dioxide capture and storage technology for the environment. This is what they have to say about it:

"Some members of our association think that the effect of carbon dioxide capture and storage technology for the environment is negative, since large amounts of chemical waste are produced with the capture of $\mathrm{CO}_{2}$. Others find that this disadvantage does not outweigh an important advantage-being that the technology reduces $\mathrm{CO}_{2}$ emissions and thereby fights climate change. They think that the 
effect of carbon dioxide capture and storage technology for the environment is positive."

After reading the information on CCS, participants indicated their attitude toward the implementation of CCS in the west of the Netherlands $(1=$ very negative, $7=$ very positive; overall $M=3.80, S D=1.05)^{2}$ and completed a cognitive (selfreport) measure and behavioral measure of cognitive closure achieved concerning the topic of CCS, an additional manipulation check of source consensus, and a number of control measures. ${ }^{3}$ At the end of the series of studies in which the participants took part, they were thanked and debriefed.

\section{Measures}

\section{Manipulation checks}

We employed the same source identity manipulation check as in Experiment 1 to check whether participants had understood the source identity manipulation correctly. To check whether participants had understood the consensus manipulation correctly, prior to reading the information from the information source they were asked to indicate whether members of the information source agree or disagree among themselves concerning the net effect of the implementation of carbon dioxide capture and storage technology for the environment $(1=$ they disagree among themselves; 2 = they agree among themselves). Moreover, at the end of the study, that is, after reading the information ostensibly provided by the source in question and completing the measures of cognitive closure achieved, participants were asked to indicate the extent to which they thought that the members of the information source disagreed or agreed among each other about the net effect of carbon dioxide capture and storage technology for the environment $(1=$ disagreed completely, $7=$ agreed completely $)$.

\section{Control measures}

We wanted to rule out the possibility that effects of our experimental manipulations might be accounted for by individual differences between participants in their overall need for closure or self-efficacy (cf. Webster \& Kruglanski, 1994). We therefore assessed these two factors as control variables after completing the actual study, presenting these measures to participants as an unrelated study on personality differences. We measured need for closure using the revised 15-item

\footnotetext{
${ }^{2}$ There were no significant main effects of or interaction effect between the source identity manipulation and the consensus manipulation on participants' (positive or negative) attitudes towards the implementation of CCS in the west of the Netherlands, $F s(1,72) \leq 1.63, p s \geq .205$.

${ }^{3}$ We checked whether counterbalancing of the source's message (positive versus negative conclusions in the consensus condition; order of arguments in the non-consensus condition) affected cognitive closure achieved. This was not the case.
}

need for closure scale developed by Roets and Van Hiel (2011) $(\alpha=.80)$. Self-efficacy was measured by means of the Dutch adaptation of the general self-efficacy scale (Teeuw, Schwarzer, \& Jerusalem, 1994), which consists of 10 items $(\alpha=.81)$. Higher scores on the 7-point scales indicate higher levels of need for closure or higher levels of self-efficacy.

Perceived source expertise. Perceived source expertise was measured using the same items as in Experiment 1 $(\alpha=.93)$.

Ability to achieve closure. Ability to achieve closure was measured with the same items as in Experiment 1 $(\alpha=.84)$.

Cognitive closure achieved. Participants' cognitive closure regarding their attitude on CCS was measured using a cognitive (self-report) measure as well as a behavioral measure, which were both virtually identical to those used in previous research on cognitive closure (Koot et al., 2014). First, participants indicated their agreement with 13 statements regarding their attitude on the implementation of CCS, such as "I am certain of my opinion on the implementation of carbon dioxide capture and storage technology in the west of the Netherlands," "I feel undecided about my opinion on carbon dioxide capture and storage technology" (reverse-coded), and "My opinion on the implementation of carbon dioxide capture and storage technology in the west of the Netherlands is fixed" ( 1 = completely disagree, 7 = completely agree $)$. A cognitive closure scale was calculated by averaging participants' responses to the items $(\alpha=.81)$, on which higher scores indicate higher levels of cognitive closure achieved.

We then assessed cognitive closure achieved with a behavioral measure, which involved asking participants to decide whether or not they were ready to participate in a poll concerning the implementation of CCS in the west of the Netherlands ( $1=I$ am ready to participate; $2=I$ am not yet ready to participate). The results of this poll would ostensibly be forwarded to governmental organizations involved in the implementation of CCS in the west of the Netherlands. After indicating whether or not they were ready to participate, participants who answered affirmatively could choose to vote for or against the implementation of CCS. Participants' decision whether or not to participate in the poll (i.e., commit to their attitude) was used as a behavioral measure of cognitive closure achieved, in which the decision to participate in the poll was regarded an indicator of cognitive closure.

\section{Results}

Descriptive statistics (means, standard deviations, and percentages) for the dependent variables as a function of source identity and consensus are presented in Table 1. 
Table 1 Means (Standard Deviations) and Percentages of Perceived Source Expertise, Ability to Achieve Closure, and Cognitive Closure Achieved as a Function of Source Identity and Consensus (Experiment 2)

\begin{tabular}{|c|c|c|c|c|}
\hline & \multicolumn{4}{|c|}{ Source identity } \\
\hline & \multicolumn{2}{|c|}{ Citizens association } & \multicolumn{2}{|c|}{ Geophysicists } \\
\hline & Consensus & Non-consensus & Consensus & Non-consensus \\
\hline Perceived source expertise & $4.28(1.29)$ & $3.56(1.07)$ & $5.66(0.72)$ & $5.33(0.85)$ \\
\hline Ability to achieve closure & $3.40(1.16)$ & $2.56(1.00)$ & $3.50(1.19)$ & $3.45(0.90)$ \\
\hline Cognitive closure achieved: self-report & $3.90(0.81)$ & $2.90(0.60)$ & $3.27(0.79)$ & $3.25(0.64)$ \\
\hline
\end{tabular}

\section{Manipulation checks}

We screened the data for incorrect answers to the factual manipulation checks of source identity and consensus (i.e., the checks that took place prior to reading the information on CCS from the information source). Ten participants answered one of the manipulation check questions incorrectly. This means that these participants had incorrectly understood the identity of the information source or had incorrectly understood that the members of the information source (dis)agreed among themselves (none of the participants answered both questions incorrectly). We excluded these cases from the analyses below. Thus, the analyses reported below were conducted on the data of 76 participants. Inclusion of all cases did not change the pattern of results.

Analysis of Variance (ANOVA) on the remaining participants' perceptions of the level of (dis)agreement among members of the information source (assessed after completion of the study) further confirmed that participants in the consensus condition clearly perceived higher consensus among source members $(M=6.23, S D=1.56)$ than participants in the non-consensus condition $(M=2.54, S D=1.61)$, $F(1,72)=98.68, p<.001, \eta_{\mathrm{p}}{ }^{2}=.58$. There was no main effect of source identity on this measure, $F(1,72)<1$, $p=.757$, nor an interaction between source identity and consensus, $F(1,72)<1, p=.818$, confirming that we were able to manipulate perceived source consensus independently from source identity.

\section{Control measures}

ANOVA showed no significant main effects of or interaction effect between source identity and consensus on need for closure or on self-efficacy, $F s(1,72) \leq 1.80$, ps $\geq .184$. Furthermore, including need for closure and self-efficacy as covariates in subsequent analyses did not change the pattern of results reported below. Thus, effects of our experimental manipulations on participants' responses cannot be ascribed to differences between conditions in need for closure or selfefficacy.

\section{Perceived source expertise}

We conducted a $2 \times 2$ ANOVA with source identity and source consensus as independent variables and perceived source expertise as the dependent variable. As in Experiment 1 , and as predicted in Hypothesis 1, results showed a significant main effect of source identity, $F(1,72)=44.43, p<.001$, $\eta_{\mathrm{p}}{ }^{2}=.38$, where participants in the Geophysicists condition ascribed higher levels of expertise to the information source $(M=5.49, S D=0.80)$ than participants in the Citizens Association condition $(M=3.96, S D=1.24)$. The analysis further revealed the predicted main effect of consensus, $F(1$, $72)=5.04, p=.028, \eta_{\mathrm{p}}{ }^{2}=.07$, where participants in the consensus condition perceived significantly higher levels of source expertise $(M=4.88, S D=1.27)$ compared to participants in the non-consensus condition $(M=4.47, S D=1.31)$. There was no significant interaction effect of source identity and consensus on perceived source expertise, $F(1,72)<1$, $p=.405$.

\section{Ability to achieve closure}

We submitted participants' perceptions concerning their ability to achieve closure on CCS to a $2 \times 2$ ANOVA with source identity and source consensus as independent variables. Consistent with our prediction (Hypothesis 1), and replicating the results of Experiment 1, the analysis revealed a significant main effect of source identity, $F(1,72)=4.08, p=.047$, $\eta_{\mathrm{p}}{ }^{2}=.05$, such that participants in the Geophysicists condition felt better able to form a closed attitude on CCS $(M=3.47, S D=1.03)$ than participants in the Citizens Association condition $(M=3.02, S D=1.15)$. Furthermore, the analysis revealed a marginally significant main effect of consensus on ability to achieve closure, with the pattern of means showing differences in the predicted direction (Hypothesis 2), $F(1,72)=3.30, p=.073, \eta_{\mathrm{p}}{ }^{2}=.04$. That is, participants in the consensus condition felt (marginally) better able to form a closed attitude on CCS $(M=3.44$, $S D=1.16)$ than participants in the non-consensus condition $(M=3.01, S D=1.04)$. There was no significant interaction 
effect between source identity and consensus on ability to achieve closure, $F(1,72)=2.57, p=.113$.

\section{Mediation analyses}

We followed a bootstrapping procedure (Preacher \& Hayes, 2008: 5000 resamples, bias corrected, controlling for consensus) to test our prediction that perceived source expertise would mediate the effect of source identity on ability to achieve closure. Consistent with Hypothesis 1 and corroborating the results of Experiment 1, the analysis showed a significant indirect effect of the source identity manipulation ( $0=$ Citizens Association, $1=$ Geophysicists $)$ on ability to achieve closure through perceived source expertise, $B=0.70$, $95 \%$ CI $(0.38,1.08)$; c' path $B=-0.21, p=.464$. This means that to the extent that people perceive an association of Geophysicists to have higher expertise on CCS than a Citizens' association, this higher level of source expertise in turn increases their ability to achieve closure on CCS.

We followed another bootstrapping procedure (Preacher \& Hayes, 2008: 5000 resamples, bias corrected, controlling for source identity) to test our second hypothesis that perceived source expertise would also mediate the effect of consensus on ability to achieve closure. Results confirmed our prediction and revealed a significant indirect effect of the consensus manipulation ( $0=$ non-consensus, $1=$ consensus $)$ on ability to achieve closure through perceived source expertise, $B=0.24,95 \% \mathrm{CI}(0.05,0.51)$; c' path $B=0.23, p=.340$, thereby providing support for Hypothesis 2. That is, these results show that to the extent that the communication of consensus (vs. non-consensus) increases people's perceptions of source expertise, this higher level of source expertise in turn increases people's ability to achieve closure on CCS.

\section{Cognitive closure achieved}

To test whether the source identity manipulation and consensus manipulation also affected the level of cognitive closure that participants actually achieved, we first conducted a $2 \times 2$ ANOVA on the self-report measure of closure achieved. Results of the analysis revealed no main effect of source identity, $F(1,72)<1, p=.397$, but did reveal a significant main effect of consensus, $F(1,72)=9.35, p=.003$, $\eta_{\mathrm{p}}{ }^{2}=.11$. This main effect was qualified by a significant interaction between source identity and consensus, $F(1$, $72)=8.77, p=.004, \eta_{\mathrm{p}}{ }^{2}=.11$. Additional analyses of simple main effects revealed that in the case of the Citizens Association, participants reported significantly higher levels of cognitive closure achieved when members of the source had communicated consensus $(M=3.90, S D=0.81)$ compared to when they had communicated disagreement (i.e., nonconsensus $)(M=2.90, \quad S D=0.60), \quad B=1.00, \quad t=4.36$, $p<.001$. In the case of the Geophysicists, however, the com- munication of consensus vs. non-consensus did not further increase the level of cognitive closure that participants achieved $(M=3.27, S D=0.79$, and $M=3.25, S D=0.64$, respectively), $B=0.02, t=0.07, p=.947$.

We also tested whether source identity and consensus affected the behavioral manifestation of cognitive closure achieved by conducting a $2 \times 2$ binary logistic regression analysis on participants' decision to participate in the poll, as a way to assess cognitive closure achieved. Results of the analysis revealed no main effect of source identity $(B=-1.07$, Wald $[1]=1.83, p=.176)$, but did show a main effect of consensus $(B=-2.17$, Wald $[1]=7.89, p=.005)$. In line with the self-report measure of cognitive closure achieved, this main effect was qualified by a marginally significant interaction effect of source identity and consensus $(B=1.75$, Wald $[1]=2.89, p=.089)$. Separate chi-squared tests for the two source identity conditions revealed that in the Citizens Association condition, participants were more likely to participate in the poll when the source had communicated consensus ( $64 \%$ decided to cast a vote) compared to nonconsensus $\left(17 \%\right.$ decided to cast a vote), $\chi^{2}(1)=8.94$, $p=.003$. In the Geophysicists condition, on the other hand, communication of (non-)consensus did not affect participants readiness to participate in the poll; $47 \%$ of participants in the consensus condition decided to cast a vote vs. $37 \%$ in the non-consensus condition, $\chi^{2}(1)=0.39, p=.535$.

\section{Additional analyses}

At first sight, it may seem inconsistent that we found two main effects on perceived expertise and ability to achieve closure (as predicted), while our measures of cognitive closure achieved revealed an interaction between these two manipulations. We conducted some additional analyses to better understand this apparent discrepancy between our observations on different measures. The ANOVAs we conducted to examine support for our predicted effects on perceived source expertise and ability to achieve closure did not revealed statistically significant interaction effects of source identity and consensus. However, further inspection of the mean scores (see Table 1) does suggest that that the effect of consensus on these measures primarily emerged in the Citizens Association condition-reflecting a pattern similar to what we observed in the two measures of cognitive closure achieved. We further explored this possibility by conducting separate ANOVAs for each of the two source identity conditions to examine the effect of the consensus manipulation on perceived source expertise and ability to achieve closure. The results of these additional analyses confirm that the added value of communicating consensus for perceived source expertise and ability to achieve closures primarily emerges when the expertise of the source is not clearly implied in its identity. That is, participants who anticipated to receive 
information from the Citizens Association perceived (marginally) higher levels of source expertise and felt significantly better able to achieve closure on CCS when this source communicated consensus $\left(M_{\text {expertise }}=4.28, S D_{\text {expertise }}=1.29\right.$; $\left.M_{\text {ability }}=3.40, S D_{\text {ability }}=1.16\right)$ compared to non-consensus $\left(M_{\text {expertise }}=3.56, \quad S D_{\text {expertise }}=1.07 ; \quad M_{\text {ability }}=2.56\right.$, $S D_{\text {ability }}=1.00$ ) (perceived source expertise: $F[1,38]=3.66$, $p=.063, \eta_{\mathrm{p}}{ }^{2}=.09 ;$ ability to achieve closure: $F[1$, $\left.38]=5.96, p=.019, \eta_{\mathrm{p}}{ }^{2}=.14\right)$. However, there was no evidence of an added value of communicating consensus when participants anticipated to receive information from the Geophysicists. That is, participants did not appear to perceive higher source expertise or feel better able to achieve closure when the Geophysicists communicated consensus $\left(M_{\text {expertise }}=5.66, \quad S D_{\text {expertise }}=0.72 ; \quad M_{\text {ability }}=3.50\right.$, $\left.S D_{\text {ability }}=1.19\right) \quad$ vs. $\quad$ non-consensus $\quad\left(M_{\text {expertise }}=5.33\right.$, $\left.S D_{\text {expertise }}=0.85 ; M_{\text {ability }}=3.45, S D_{\text {ability }}=0.90\right)$ (perceived source expertise: $F[1,34]=1.59, p=.216$; ability to achieve closure: $F[1,38]<1, p=.881)$. Moreover, when we conducted separate bootstrapping analyses for each of the two source identity conditions (Preacher \& Hayes, 2008: 5000 resamples, bias corrected) this revealed that perceived expertise mediated the effect of the source consensus manipulation ( $0=$ non-consensus, $1=$ consensus $)$ on ability to achieve closure in the Citizens Association condition $(B=0.31 ; 95 \%$ CI $[0.03,0.76]$; c' path $B=0.54, p=.107)$. Again, no such indirect effect occurred in the Geophysicists condition $(B=0.13 ; 95 \%$ CI $[-0.03,0.47] ; \quad c$ path $B=-0.10$, $p=.770)$. Taken together, these additional analyses consistently suggest that the communication of consensus primarily increases perceptions of source expertise-and thus increases the ability to achieve closure-when the identity of the source does not (already) contain clear indications of high expertise (e.g., in the case of a lay information source).

\section{Discussion}

In sum, the results of Experiment 2 replicate and extend those of the first study, and offer support both Hypothesis 1 and Hypothesis 2. The findings again show the importance of perceived source expertise for people's ability to achieve closure on complex environmental topics, and demonstrate that both source identity and the communication of consensus can contribute to perceptions of source expertise. As in Experiment 1, we found that the identity of an information source influences perceptions of source expertise, and that higher levels of perceived source expertise in turn increase people's ability to form a closed attitude on a complex topic. Additionally, Experiment 2 reveals that for perceptions of source expertise, and thereby for people's ability to achieve closure, it is not only important who is providing the information, but also what message is being communicated. That is, we found that people regard an information source to have more expertise, and therefore feel better able to achieve closure, when it communicates consensus rather than nonconsensus. Notably, the effects observed in the present research emerged independently of individual differences in need for closure or self-efficacy. This allows us to rule out such differences as alternative explanations for our findings, and suggests that people's ability to achieve closure may be affected by source factors, regardless of existing variations in people's individual needs and abilities relevant to the formation of a closed attitude. Finally, although the effects of source identity and consensus occurred independently of one another as predicted, results on cognitive closure achieved and additional analyses suggest that that the added value of communicating consensus primarily emerges for sources with a non-expert identity.

\section{General discussion}

Compared to open, "unfinished" attitudes, closed attitudes are better predictors of people's future attitudes and behavior (cf. Krosnick \& Petty, 1995; Petty \& Cacioppo, 1986). As such, closed attitudes-attitudes on which people have achieved a state of cognitive closure-are better predictors of people's support for or opposition to complex environmental policies and technologies. In the present work, we examined whether and how source factors in communication impact on people's perceived ability to achieve closure in their attitude formation. Specifically, we examined the impact of the level of expertise that people perceive an information source to have on their ability to form a closed attitude on complex environmental topics. We also examined source identity and consensus as potential cues to source expertise.

The current research shows that that when people perceive a source of information to have a high level of expertise on the topic in question, they feel more capable of forming a closed attitude on the basis of the information provided by this source. Our results also demonstrate that perceived source expertise not only depends on who is communicating, but is also affected by the message communicated by this source. People attribute higher expertise to an information source that has an expert identity (i.e., geophysicists) compared to a non-expert identity (i.e., a citizens association). Likewise, a source that communicates consensus, rather than non-consensus, is judged as having more expertise on the topic in question, enhancing people's ability to form an attitude on the basis of the information provided by this source. The added value of communicating consensus for perceived source expertise and ability to achieve closure occurs in particular for information sources whose identity suggests lowexpertise.

The present research contributes to existing insights in several ways. First, it shows that source factors in communication may enhance people's ability to achieve cognitive 
closure. Previous research on the ability to achieve closure has shown that the extent to which people perceive themselves able to achieve closure in their attitude formation is susceptible to external influences. However, this work employed relatively artificial manipulations (e.g., bogus feedback from a personality test; Koot et al., 2014) to induce such differences and therefore has limited ecological validity. To our knowledge, the current research is the first to reveal how experiences that are more likely to emerge in real life settings can enhance or impede people's ability to make up their mind. In this way, the present results corroborate and extend emerging evidence that the ability to achieve closure not only indicates how individuals differ from each other, but is also a factor that can be influenced situationally, independently of more stable individual differences.

The observed effects of source identity and consensus on the ability to achieve closure through perceived source expertise extend existing insights on source factors in attitude change (e.g., Briñol \& Petty, 2009; Clarkson et al., 2008; Horcajo et al., 2010; Tormala \& DeSensi, 2009). That is, whereas previous studies examined the impact of source factors on thought confidence and attitude certainty, the present work addressed how source factors influence people's ability to achieve closure. Our results suggest that source identity and the communication of consensus also affect the level of expertise that people ascribe to an information source. Higher levels of perceived source expertise in turn increase the extent to which people feel able to form a closed attitude on the topic in question.

In the present research, we established that people form an impression about the expertise of a particular source of information on the basis of its identity. At first sight, this may seem self-evident, and indeed, there are several studies in which source identity and source expertise are treated as interchangeable concepts (e.g., Bohner, Ruder, \& Erb, 2002; Clark, Wegener, Habashi, \& Evans, 2012; Mackie \& Worth, 1989). However, the current research also demonstrates that the level of expertise that people attribute to a particular information source is not fixed. Instead, we demonstrated that the perceived level of expertise of a given source is also affected by the content of its message (cf. Reimer et al., 2004) — in this case the level of consensus communicated by the source. This extends current insights on the impact of consensus for persuasion (e.g., Darke et al., 1998; Eagly \& Chaiken, 1993; Prislin et al., 2012; Ziegler et al., 2004). We found that the communication of internal agreement enhances the perceived expertise of the source, and this is particularly relevant when such expertise is not yet implied in the identity of the source. Communicating consensus adds less to perceived expertise of a source whose expertise is already implied in its identity. The observation that source identity can moderate consensus effects is a relevant addition to exist- ing insights, and illustrates the importance of examining two or more source factors combined.

We have interpreted the results of our studies as indicating that the communication of (non-)consensus mainly affects perceived source expertise and ability to achieve closure when such confidence cannot be derived from the identity of the source. Nevertheless, we acknowledge that the present data are not conclusive on this point. Instead, they may reflect the specific nature of the manipulation we used to convey (lack of) consensus. While we indicated that there was disagreement on what can be concluded about the net consequences of carbon dioxide capture and storage (CCS) for the environment, there was no sign of disagreement about the underlying facts. This form of disagreement may not have seemed very strong or problematic. Indeed, on the basis of the present work, we cannot exclude the possibility that a stronger level of disagreement might also undermine people's reliance on information provided by an expert source. We conducted an auxiliary study to explore this. In this study, members of "The Association of Dutch Geophysicists and Sustainability" were said to agree or disagree about the facts underlying their stance towards CCS. In support of our current interpretation of the present findings, and similar to what we observed in Experiment 2, this stronger manipulation of (lack of) consensus did not affect perceived source expertise to such an extent that it lead to a significant decrease in people's ability to achieve closure on the topic. Thus, the available evidence suggests that an expert identity indeed is quite a robust indicator of high expertise. Additional research can further address this question, and more systematically establish the boundary conditions for this effect.

When trying to ascertain the broader implications of our current findings, we acknowledge that the particular nature of our sample may have played a role in the responses we observed. Participants in the current research were Dutch university students. They deviate from a random sample of the general public in a number of ways. First, they may be more used to, and hence overall more confident to, forming opinions on the basis of partial or inconsistent information. Indeed, as part of their academic training, they are prepared to deal with scientific nuance and to weigh the positions of experts advocating diverging points of view. This may have made our participants relatively unmoved by the communication of (non-)consensus in the case of an expert source. On the other hand, a more representative sample of the general population is likely to be more impressed with the expertise of geophysicists than university students who are used to interact with and question different types of experts, so our findings can be seen as "conservative." We acknowledge the specific nature of our sample, and future research might establish the broader applicability of these findings. 
In this research, we made sure that the two source factors under investigation (source identity and consensus) were both equally salient to research participants, and that the CCS topic of the study was relevant for participants, as we wanted participants to evaluate the source of information and think about their ability to achieve cognitive closure on the basis of information provided. Yet this set-up may limit the generalizability of our findings to more naturalistic settings. At the same time, we know that when people form an opinion about a novel technology that has consequences for their direct environment their involvement is often high (e.g., Terwel, Ter Mors, \& Daamen, 2012). As a result, they tend to consider whether different parties can be trusted, or which information source they can rely on. Thus, similar high involvement situations in which people are motivated to form an opinion and are critical towards information sources are common and occur in real life. We acknowledge that the questions we asked made the source more salient, but this was the case in all experimental conditions, and cannot account for effects observed in the present studies. The fact that we did not only find effects on self-report measures of ability to achieve closure and cognitive closure in Experiment 2-but also on a behavioral (and more implicit) measure of cognitive closure also suggests that the results are not driven by demand effects.

The current research raises questions for further theory development as well as future applications. One question to address in future research is whether the identity and degree of consensus of the information source needs to be made salient for these effects to occur. It would also be relevant to examine whether expert stakeholders actually involved in complex issues or projects can manage their reputations and further increase the (relative) impact of their communications by emphasizing their expert identity or explicitly stating internal consensus.

We conclude that the level of expertise that people perceive an information source to have is an important determinant of how capable they feel of forming a closed attitude on environmental complex topics. The identity of an information source emerges as a relevant cue to its expertise which impacts people's ability to achieve closure. However, especially when the source has no expert identity, its perceived expertise may also be enhanced by communicating consensus about the topic in question.

\section{Acknowledgment}

This research was carried out in the context of the CATO-2program. CATO-2 is the Dutch national research program on $\mathrm{CO}_{2}$ Capture and Storage technology (CCS). The program is financially supported by the Dutch government (Ministry of Economic Affairs) and the CATO-2 consortium parties. This research was carried out while Naomi Ellemers was at Leiden University.

\section{References}

Bandura, A. (1977). Self-efficacy: Toward a unifying theory of behavioral change. Psychological Review, 84, 191-215. doi: 10.1037/0033-295X.84.2.191

Bandura, A. (2006). Toward a psychology of human agency. Perspectives on Psychological Science, 1, 164-180. doi:10.1111/ j.1745-6916.2006.00011.x

Bassili, J. N. (1996). Meta-judgmental versus operative indexes of psychological attributes: The case of measures of attitude strength. Journal of Personality and Social Psychology, 71, 637-653. doi:10.1037/00223514.71.4.637

Bohner, G., \& Dickel, N. (2011). Attitudes and attitude change. Annual Review of Psychology, 62, 391-417. doi:10.1146/ annurev.psych.121208.131609

Bohner, G., Ruder, M., \& Erb, H.-P. (2002). When expertise backfires: Contrast and assimilation effects in persuasion. British Journal of Social Psychology, 41, 495-519.
Briñol, P., \& Petty, R. E. (2009). Source factors in persuasion: A self-validation approach. European Review of Social Psychology, 20, 49-96. doi:10.1080/ 10463280802643640

Cialdini, R. B., \& Goldstein, N. J. (2004). Social influence: Compliance and conformity. Annual Review of Psychology, 55, 591-621. doi:10.1037/00219010.74.2.247

Clark, J. K., Wegener, D. T., Habashi, M. M., \& Evans, A. T. (2012). Source expertise and persuasion: The effects of perceived opposition or support on message scrutiny. Personality and Social Psychology Bulletin, 38, 90-100.

Clarkson, J. J., Tormala, Z. L., \& Rucker, D. D. (2008). A new look at the consequences of attitude certainty: The amplification hypothesis. Journal of Personality and Social Psychology, 95, 810-825.

Crano, W. D., \& Seyranaion, V. (2007). Majority and minority influence. Social and Personality Psychology Compass, 1, 572-589.
Darke, P. R., Chaiken, S., Bohner, G., Einwiller, S., Erb, H.-P, \& Hazlewood, J. D. (1998). Accuracy motivation, consensus information, and the law of large numbers: Effects on attitude judgement in the absence of augmentation. Personality and Social Psychology Bulletin. 24, 1205-2015. Retrieved from http://psp.sagepub.com/content/24/11/1205.short

Eagly, A. H., \& Chaiken, S. (1993). The psychology of attitudes. Forth Worth, TX: Harcourt.

Fazio, R. H., \& Zanna, M. P. (1978). Attitudinal qualities relating to the strength of the attitude-behavior relationship. Journal of Experimental Social Psychology, 14, 398-408.

Horcajo, J., Petty, R. E., \& Briñol, P. (2010). The effects of majority versus minority status on persuasion: A self-validation analysis. Journal of Personality and Social Psychology, 99, 498-512. doi:10.1037/ a0018626

IPCC. (2007). Summary for policymakers. In B. Metz, O. R. Davidson, P. R. Bosch, 
R. Dave, \& L. A. Meyer (Eds.), Climate change 2007: Mitigation. Contribution of working group III to the fourth report of the intergovernmental panel on climate change (pp. 7-22). Cambridge and New York, NY: Cambridge University Press.

Koot, C., Ter Mors, E., Ellemers, N., \& Daamen, D. D. L. (2014). Antecedents and consequences of achieving cognitive closure: The ability to achieve closure, and openness to additional information. Manuscript submitted for publication.

Kossowska, M., \& Bar-Tal, Y. (2013). Need for closure and heuristic information processing: The moderating role of the ability to achieve the need for closure. British Journal of Psychology, 104, 457480. doi:10.1111/bjop.12001

Kossowska, M., Dragon, P., \& Bukowski, M. (2015). When need for closure leads to positive attitudes towards a negatively stereotyped outgroup. Motivation and Emotion, 29, 88-98. Retrieved from http://link.springer.com/article/10.1007/ s11031-014-9414-5

Krosnick, J. A., \& Petty, R. E. (1995). Attitude strength: An overview. In R. E. Petty \& J. A. Krosnick (Eds.), Attitude strength: Antecedents and consequences (pp. 1-24). Hillsdale, NJ: Erlbaum.

Kruglanski, A. W., Dechesne, M., Orehek, E., \& Pierro, A. (2009). Three decades of lay epistemics: The why, how, and who of knowledge formation. European Review of Social Psychology, 20, 146-191. doi:10.1080/10463280902860037

Kruglanski, A. W., \& Thompson, E. P. (1999). Persuasion by a single route: A view from the unimodel. Psychological Inquiry, 10, 83-109.

Kruglanski, A. W., \& Webster, D. M. (1996). Motivated closing of the mind: "Seizing" and "freezing". Psychological Review, 103, 263-283.

Mackie, D. M., \& Worth, L. T. (1989). Processing deficits and the mediation of positive affect in persuasion. Journal of Personality and Social Psychology, 57, 27-40.

Markusson, N., Ishii, A., \& Stephens, J. C. (2011). The social and political complex- ities of learning in carbon capture and storage demonstration projects. Global Environmental Change, 21, 293-302.

Petty, R. E., \& Cacioppo, J. T. (1986). The elaboration likelihood model of persuasion. In L. Berkowitz (Ed.), Advances in experimental social psychology (pp. 123205). New York: Academic Press.

Pornpitakpan, C. (2004). The persuasiveness of source credibility: A critical review of five decades' evidence. Journal of Applied Social Psychology, 34, 243-281. doi:10.1111/j.1559-1816.2004.tb02547.x

Preacher, K. J., \& Hayes, A. F. (2008). Asymptotic and resampling strategies for assessing and comparing indirect effects in multiple mediator models. Behavior Research Methods, 40, 879-891. doi: 10.3758/BRM.40.3.879

Prislin, R., Shaffer, E., \& Crowder, M. (2012). Populism vs. elitism: Social consensus and social status as bases of attitude certainty. The Journal of Social Psychology, 152, 327-339.

Reimer, T., Mata, R., \& Stoecklin, M. (2004). The use of heuristics in persuasion: Deriving cues on source expertise from argument quality. Current Research in Social Psychology, 10. Retrieved from http://www.uiowa.edu/ grpproc/crisp/ crisp.10.6.html

Roets, A., \& Soetens, B. (2010). Need and ability to achieve closure: Relationships with symptoms of psychopathology. Personality and Individual Differences, 48, 155-160.

Roets, A., \& Van Hiel, A. (2007). Separating ability from need: Clarifying the dimensional structure of the need for closure scale. Personality and Social Psychology Bulletin, 33, 266-280. doi:10.1177/ 0146167206294744

Roets, A., \& Van Hiel, A. (2011). Item selection and validation of a brief, 15-item version of the need for closure scale. Personality and Individual Differences, 50, 90-94.

Teeuw, B., Schwarzer, R., \& Jerusalem, M. (1994). Dutch adaptation of the general self-efficacy scale. Retrieved November
12, 2010, from http://userpage.fu-berlin. de/ health/dutch.htm

Ter Mors, E., Weenig, M. W. H., Ellemers, E., \& Daamen, D. D. L. (2010). Effective communication about complex environmental issues: Perceived quality of information about carbon dioxide capture and storage depends on stakeholder collaboration. Journal of Environmental Psychology, 30, 347-357. doi:10.1016/ j.jenvp.2010.06.001

Terwel, B. W., Ter Mors, E., \& Daamen, D. D. L. (2012). It's not only about safety: Beliefs and attitudes of 811 local residents regarding a CCS project in Barendrecht. International Journal of Greenhouse Gas Control, 9, 41-51. doi: 10.1016/j.ijggc.2012.02.017

Tormala, Z. L., \& DeSensi, V. L. (2009). The effects of majority/minority status on attitude certainty: A matching perspective. Personality and Social Psychology Bulletin, 35, 114-125. doi:10.1177/ 0146167208325677.

Van Egmond, S., \& Hekkert, M. P. (2012). Argument map for carbon capture and storage. International Journal of Greenhouse Gas Control, 11, S148-S159. doi: 10.1016/j.ijggc.2012.08.010

Webster, D. M., \& Kruglanski, A. W. (1994). Individual differences in need for cognitive closure. Personality Processes and Individual Differences, 67, 1049-1062.

Webster, D. M., \& Kruglanski, A. W. (1997). Cognitive and social consequences of the need for cognitive closure. European Review of Social Psychology, 8, 133-161.

Wood, W., Lundgren, S., Quelette, J. A., Busceme, S., \& Blackstone, T. (1994). Minority influence: A meta-analytic review of social influence processes. Psychological Bulletin, 115, 323-345.

Ziegler, R., Diehl, M., Zigon, R., \& Fett, T. (2004). Source consistency, distinctiveness, and consensus: The three dimensions of the Kelley ANOVA model in persuasion. Personality and Social Psychology Bulletin, 30, 352-364. 